\title{
Thermoporoelastic effects during heat extraction from low-permeability reservoirs
}

\author{
Salimzadeh, Saeed; Nick, Hamidreza M.; Zimmerman, R. W.
}

\section{Published in:}

Energy

Link to article, DOI:

10.1016/j.energy.2017.10.059

Publication date:

2018

Document Version

Peer reviewed version

Link back to DTU Orbit

Citation (APA):

Salimzadeh, S., Nick, H. M., \& Zimmerman, R. W. (2018). Thermoporoelastic effects during heat extraction from low-permeability reservoirs. Energy, 142, 546-558. https://doi.org/10.1016/j.energy.2017.10.059

\section{General rights}

Copyright and moral rights for the publications made accessible in the public portal are retained by the authors and/or other copyright owners and it is a condition of accessing publications that users recognise and abide by the legal requirements associated with these rights.

- Users may download and print one copy of any publication from the public portal for the purpose of private study or research.

- You may not further distribute the material or use it for any profit-making activity or commercial gain

- You may freely distribute the URL identifying the publication in the public portal

If you believe that this document breaches copyright please contact us providing details, and we will remove access to the work immediately and investigate your claim. 


\title{
Thermoporoelastic Effects during Heat Extraction from Low- Permeability Reservoirs
}

\author{
Saeed Salimzadeh ${ }^{1}$, Hamidreza M. Nick ${ }^{1}$, R.W. Zimmerman ${ }^{2}$ \\ ${ }^{1}$ Danish Hydrocarbon Research and Technology Centre, Technical University of Denmark, \\ Lyngby, Denmark \\ ${ }^{2}$ Department of Earth Science and Engineering, Imperial College, London, UK
}

\begin{abstract}
Thermoporoelastic effects during heat extraction from low permeability geothermal reservoirs are investigated numerically, based on the model of a horizontal penny-shaped fracture intersected by an injection well and a production well. A coupled formulation for thermo-hydraulic $(\mathrm{TH})$ processes is presented that implicitly accounts for the mechanical deformation of the poroelastic matrix. The TH model is coupled to a separate mechanical contact model (M) that solves for the fracture contact stresses due to thermoporoelastic compression. Fractures are modelled as surface discontinuities within a three-dimensional matrix. A robust contact model is utilised to resolve the contact tractions between opposing fracture surfaces. Results show that due to the very low thermal diffusivity of the rock matrix, the thermally-induced pore pressure partially dissipates even in the very low-permeability rocks that are found in EGS projects. Therefore, using the undrained thermal expansion coefficient for the matrix may overestimate the volumetric strain of the rock in lowpermeability enhanced geothermal systems, whereas using a drained thermal expansion coefficient for the matrix may underestimate the volumetric strain of the rock. An "effective" thermal expansion coefficient can be computed from the drained and undrained values to improve the prediction for the partially-drained matrix.
\end{abstract}

Keywords: Coupled formulation; low-permeability rock; enhanced geothermal systems; undrained thermal expansion coefficient 


\section{INTRODUCTION}

Across a significant percentage of the Earth's surface, the subsurface is hot enough to be used for geothermal electricity production (McClure and Horne, 2014). In deep geothermal reservoirs, the formations are typically of very low permeability, and fractures, natural or man-made, are needed to enhance the fluid flow within these reservoirs. Multiple physical processes including thermal $(\mathrm{T})$, hydro $(\mathrm{H})$, and mechanical $(\mathrm{M})$ processes influence heat extraction from fractured geothermal systems (Tsang, 1991; MIT, 2006). In fractured geothermal systems, short-circuiting may occur due to thermoporoelastic deformation of the rock matrix, and a direct flow pathway may then connect the injector and producer. The rock formation cools down in the vicinity of the short-circuit pathway, leading to lower heat production from the reservoir.

Thermal fracturing has been observed in many subsurface applications, wherein a relatively cold fluid has been injected into a reservoir: for instance, in water injection wells in the petroleum industry (Bellarby, 2009), in geothermal wells (Benson et al., 1987; Tulinius et al., 2000), and even in relatively soft, unconsolidated formations (Santarelli et al., 2008). In enhanced geothermal systems (EGS), the stimulation can occur through induced slip on preexisting fractures (shear stimulation), by creating new fractures using hydraulic fracturing (opening mode), or by a combination of the two processes (McClure and Horne, 2014). Fluid flow through a fracture is governed by the cubic law, which is derived from the general Navier-Stokes equation for flow of a fluid between two parallel plates (Zimmerman and Bodvarsson, 1996). Thus, variations in fracture aperture due to the changes in the normal and/or shear stresses acting on the fracture surfaces as a result of the THM processes strongly affect the fluid flow and heat transport in the fracture (Rutqvist et al., 2005). Also, the equivalent permeability of fractured reservoirs can be significantly affected by the choice of the aperture distribution model (Bisdom et al., 2016).

Considerable efforts have been expended in developing THM models for geothermal reservoirs over the past several decades (McDermott et al., 2006; Ghassemi and Zhou, 2011; Guo et al., 2016, Wu et al., 2017). Improved injectivity and creation of flow channelling has been observed in several THM coupled simulations of fractured geothermal reservoirs (Hicks et al., 1996; Koh et al., 2011; Fu et al., 2015). The contraction of the formation due to heat extraction in the vicinity of the flow paths depends on the volumetric thermal expansion coefficient of the rock, as well as that of the fluid, if dissipation of the thermally-induced pore pressure is prevented - i.e., undrained conditions. In modelling low-permeability geothermal reservoirs such as are used in EGS, often fluid flow through the matrix is ignored, and a "drained" or an "undrained" thermal expansion coefficient is assumed for the saturated matrix. The undrained thermal expansion coefficient accounts for the poroelastic effect of the pressurised fluid "trapped" in the pores (McTigue, 1986). The induced fluid pressure is a result of the contrast between the thermal expansion of the rock and that of the fluid. 
However, due to the very low thermal diffusivity of rocks, the condition for the fluid is actually not fully "undrained", even in very low-permeability rocks in EGS projects. Using the undrained thermal expansion coefficient may overestimate the volumetric expansion (contraction) of the rock matrix, as the fluid often has a higher thermal expansion coefficient than the rock matrix, while using the drained thermal expansion coefficient may underestimate the volumetric expansion (contraction) of the rock matrix in cases of a very low-permeability matrix.

The fully coupled hydromechanical (HM) and thermo-hydromechanical (THM) models were previously presented in Salimzadeh et al. (2017 a, b) and Salimzadeh et al. (2017c). The HM model was utilised for modelling hydraulic fracturing in poroelastic media including the interactions between multiple fractures, whereas the THM model was utilised to simulate conventional geothermal reservoirs with deformable fractures. In the present study, a new coupled thermo-hydraulic (TH) model is developed that implicitly accounts for matrix volumetric deformations. Mechanical deformation as well as contact stresses on the fracture surfaces under compression are solved separately in a mechanical contact model (M). Then, the two TH and M models are further coupled sequentially. Using this approach, the computational time is reduced and modelling of reservoirs with ultra-low permeability, as are used in EGS, is feasible. Fractures are modelled as 2D surface discontinuities within the 3D rock matrix. Separate but coupled flow/heat models are defined for the fracture and the rock matrix. The flow through the fractures is governed by the cubic law, and is coupled to Darcy flow in rock matrix using a leakoff mass exchange that is computed as a function of the fracture and matrix fluid pressures, and the matrix permeability. Fracture apertures are evaluated using the classic Barton-Bandis model (Bandis et al., 1983; Barton et al., 1986), where the contact stresses are imported from the mechanical contact model (M). Local thermal non-equilibrium is considered between the fluid in the fracture and the fluid in the rock matrix. Advective-diffusive heat transfer is assumed in both the fractures and rock matrix. Heat transfer between the fracture and matrix is allowed by conduction through the fracture walls, as well as by advection through the leakoff flow. The computed fluid pressures in the fracture and matrix, and the fluid and matrix temperatures from the TH model, are considered in solving the equilibrium equation for the mechanical contact model. The coupled model has been validated against several available solutions, and applied to investigate the extent of validity of the "undrained condition" assumption for the matrix fluid in low-permeability fractured geothermal reservoirs.

\section{COMPUTATIONAL MODEL}

\subsection{Implicitly-Coupled Governing Equations}

The fully coupled poroelastic and thermoporoelastic models for discrete fractures in a deformable medium has been presented by Salimzadeh et al. (2017a, b) and Salimzadeh et al. 
(2016, 2017c), respectively. The fractures are modelled as discontinuous surfaces in the three-dimensional matrix, and a contact model is utilised to compute the contact tractions on the fracture surfaces under thermoporoelastic compression. Under specific conditions, the fully coupled thermoporoelastic formulation can be decoupled, to reduce the computational cost. In this study, the mechanical deformation and contact tractions are solved in a mechanical contact model (M) while the non-isothermal flow though three-dimensional matrix with discrete fractures are solved in a thermo-hydraulic (TH) model.

The fully coupled governing equations for non-isothermal flow through deformable matrix with discrete fractures can be written as (Salimzadeh et al., 2017c)

Mechanical deformation:

$$
\int_{\Omega}\left[\operatorname{div}\left(\mathbf{D} \boldsymbol{\varepsilon}-\alpha p_{m} \mathbf{I}-\beta_{s} K\left(T_{m}-T_{0}\right) \mathbf{I}\right)+\mathbf{F}\right] d \Omega+\int_{\Gamma_{c}}\left(\boldsymbol{\sigma}_{c}-p_{f} \mathbf{n}_{c}\right) d \Gamma=0
$$

Fluid flow through matrix:

$$
\begin{array}{r}
\int_{\Omega} \operatorname{div}\left(\frac{\mathbf{k}_{m}}{\mu_{f}}\left(\nabla p_{m}+\rho_{f} \mathbf{g}\right)\right) d \Omega= \\
\int_{\Omega}\left[\alpha \frac{\partial(\operatorname{div} \mathbf{u})}{\partial t}+\left(\phi c_{f}+\frac{\alpha-\phi}{K_{s}}\right) \frac{\partial p_{m}}{\partial t}-\left((\alpha-\phi) \beta_{s}+\phi \beta_{f}\right) \frac{\partial T_{m}}{\partial t}\right] d \Omega+\int_{\Gamma_{c}} \frac{k_{n}}{\mu_{f}} \frac{\partial p}{\partial \mathbf{n}_{c}} d \Gamma
\end{array}
$$

Heat transfer through matrix:

$$
\begin{gathered}
\int_{\Omega} \operatorname{div}\left(\lambda_{m} \nabla T_{m}\right) d \Omega=\int_{\Omega}\left[\rho_{m} C_{m} \frac{\partial T_{m}}{\partial t}-\beta_{s} K T_{m} \frac{\partial(\operatorname{div} \mathbf{u})}{\partial t}-\phi \beta_{f} T_{m} \frac{\partial p_{m}}{\partial t}+\rho_{f} C_{f} \mathbf{v}_{m} \nabla T_{m}\right] d \Omega \\
+\int_{\Gamma_{c}}\left[\lambda_{n} \frac{\partial T}{\partial \mathrm{n}_{c}}+\rho_{f} C_{f} \frac{k_{n}}{\mu_{f}} \frac{\partial p}{\partial \mathrm{n}_{c}}\left(T_{m}-T_{f}\right)\right] d \Gamma
\end{gathered}
$$

Fluid flow through fracture:

$$
\operatorname{div}\left(\frac{a_{f}^{3}}{12 \mu_{f}} \nabla p_{f}\right)=\frac{\partial a_{f}}{\partial t}+a_{f} c_{f} \frac{\partial p_{f}}{\partial t}-a_{f} \beta_{f} \frac{\partial T_{f}}{\partial t}-\frac{k_{n}}{\mu_{f}} \frac{\partial p}{\partial \mathbf{n}_{c}}
$$

Heat transfer through fracture:

$$
\begin{aligned}
& \operatorname{div}\left(a_{f} \lambda_{f} \nabla T_{f}\right)= \\
& \quad a_{f} \rho_{f} C_{f} \frac{\partial T_{f}}{\partial t}-a_{f} \beta_{f} T_{f} \frac{\partial p_{f}}{\partial t}+a_{f} \rho_{f} C_{f} \mathbf{v}_{f} . \nabla T_{f}-\lambda_{n} \frac{\partial T}{\partial \mathbf{n}_{c}}+\rho_{f} C_{f} \frac{k_{n}}{\mu_{f}} \frac{\partial p}{\partial \mathbf{n}_{c}}\left(T_{f}-T_{m}\right)
\end{aligned}
$$

in which $\mathbb{D}$ is the drained stiffness matrix, $\boldsymbol{\varepsilon}$ is the strain, $\alpha$ is the Biot coefficient, $p_{m}$ is the fluid pressure in the rock matrix, i.e., the matrix pressure, $\mathbf{I}$ is the second-order identity tensor, $K$ is bulk modulus of rock, $\beta_{s}$ is the volumetric thermal expansion coefficient of the rock matrix, $T_{m}$ is the matrix temperature, $T_{0}$ is the initial temperature, $\mathbf{F}$ is the body force per unit volume, $p_{f}$ is the fracture pressure, $\mathbf{n}_{c}$ is the outward unit normal to the fracture surface (on both sides of the fracture), $\boldsymbol{\sigma}_{c}$ is the contact traction on the fracture surface, $\mathbf{k}_{m}$ is the intrinsic permeability tensor of the rock matrix, $\mu_{f}$ is the fluid viscosity, $\mathbf{g}$ is the vector of gravitational acceleration, $\rho_{f}$ is the fluid density, $\mathbf{u}$ is the displacement vector of the rock matrix, $\phi$ is the rock matrix porosity, $c_{f}$ and $\beta_{f}$ are coefficients of the fluid compressibility and volumetric thermal expansion, respectively, $k_{n}$ is the intrinsic permeability of the rock 
matrix in the direction normal to the fracture (in the direction of $\mathbf{n}_{c}$ ), $\boldsymbol{\lambda}_{m}$ is the average thermal conductivity tensor of the matrix, $C_{f}$ is the fluid heat capacity, $\mathbf{v}_{m}$ is the fluid velocity in matrix, $\rho_{m}$ is the average density of the matrix (saturated rock), $C_{m}$ is the average matrix heat capacity, $\lambda_{n}$ is the average thermal conductivity of the rock matrix along the direction normal to the fracture (in the direction of $\mathbf{n}_{c}$ ), $a_{f}$ is the fracture aperture, $T_{f}$ is the temperature of the fluid in fracture, $\mathbf{v}_{f}$ is the fluid velocity in fracture, and $\boldsymbol{\lambda}_{f}$ is the thermal conductivity tensor of the fluid. The last terms in Eqs (2-4) represent the mass and heat transfer between the fracture and matrix (Salimzadeh and Khalili, 2015; 2016).

It can be noted that fluid flow and heat transfer equations for the matrix, Eqs. (2) and (3), contain a term for the rate of volumetric strain, $\partial(\operatorname{div} \mathbf{u}) / \partial t$, which is defined in terms of the displacement vector. For subsurface flow engineering problems, the volumetric strain can be implicitly defined based on the matrix pressure and temperature as follows. The effective stress for a rock matrix saturated with a single-phase fluid is defined as (Biot, 1941)

$$
\boldsymbol{\sigma}^{\prime}=\boldsymbol{\sigma}+\alpha p_{m} \mathbf{I}
$$

where $\boldsymbol{\sigma}^{\prime}$ is the effective stress, and the Biot coefficient is defined as

$$
\alpha=1-\frac{K}{K_{S}}
$$

where $K_{S}$ is the bulk modulus of rock matrix material (Zimmerman, 2000). In many subsurface flow engineering problems, the total stress in the rock matrix remains unchanged during the lifetime of the process (Khalili and Valliappan, 1991), so the change in effective stress will be a function of the change in matrix pressure, according to

$$
d \boldsymbol{\sigma}^{\prime}=\alpha d p_{m} \mathbf{I}
$$

The stress-strain relationship for thermoporoelasticity is written as (Khalili and Selvadurai, 2003)

$$
\boldsymbol{\sigma}^{\prime}=\mathbb{D} \boldsymbol{\varepsilon}-\beta_{s} K\left(T_{m}-T_{0}\right) \mathbf{I}
$$

and the volumetric strain of the rock matrix can be written as

$$
\operatorname{div} \mathbf{u}=\frac{1}{K} \overline{\sigma^{\prime}}+\beta_{S}\left(T_{m}-T_{0}\right)
$$

where $\overline{\sigma^{\prime}}=\left(\sigma^{\prime}{ }_{1}+\sigma_{2}^{\prime}+\sigma_{3}^{\prime}\right) / 3$ is the mean effective stress. Finally, the rate of change of the volumetric strain of the matrix can be written as

$$
\frac{\partial(\operatorname{div} \mathbf{u})}{\partial t}=\frac{\alpha}{K} \frac{\partial p_{m}}{\partial t}+\beta_{S} \frac{\partial T_{m}}{\partial t}
$$

When two surfaces of a fracture are in partial contact at the micro-scale, the mean aperture of the fracture is a function of the normal contact stress. In this study, the classic Barton-Bandis model (Bandis et al., 1983; Barton et al., 1986) is used to calculate the fracture aperture under contact stress:

$$
a_{f}=a_{0}-\frac{a \sigma_{n}}{1+b \sigma_{n}}
$$


where $\sigma_{n}$ is the normal contact stress, $a_{0}$ is the fracture aperture at zero contact stress, and $a$ and $b$ are model parameters. The normal contact stress is directly given by the contact tractions in the contact mechanical model. In the fracture flow model (Eq. 4), the change in aperture can be approximated from the change in the fluid pressure in the fracture as

$$
\frac{\partial a_{f}}{\partial t}=\frac{1}{K_{n}} \frac{\partial p_{f}}{\partial t}
$$

in which $K_{n}$ is the fracture tangent stiffness (normal), given by

$$
K_{n}=-\frac{\partial \sigma_{n}}{\partial a_{f}}=\frac{\left(1+b \sigma_{n}\right)^{2}}{a}
$$

Finally, the implicitly-coupled thermo-hydro-mechanical model can be written as follows.

Mechanical deformation:

$$
\begin{gathered}
\int_{\Omega}[\operatorname{div}(\mathbf{D} \boldsymbol{\varepsilon})+\mathbf{F}] d \Omega=\int_{\Omega}\left[\operatorname{div}\left(\alpha p_{m} \mathbf{I}\right)\right] d \Omega+\int_{\Omega}\left[\operatorname{div}\left(\beta_{s} K\left(T_{m}-T_{0}\right) \mathbf{I}\right)\right] d \Omega+ \\
\int_{\Gamma_{c}}\left(p_{f} \mathbf{n}_{c}-\boldsymbol{\sigma}_{n}\right) d \Gamma
\end{gathered}
$$

Fluid flow through matrix:

$$
\begin{gathered}
\int_{\Omega} \operatorname{div}\left[\frac{\mathbf{k}_{m}}{\mu_{f}}\left(\nabla p_{m}+\rho_{f} \mathbf{g}\right)\right] d \Omega=\int_{\Omega}\left[\left(\frac{\alpha^{2}}{K}+\phi c_{f}+\frac{\alpha-\phi}{K_{s}}\right) \frac{\partial p_{m}}{\partial t}+\phi\left(\beta_{s}-\beta_{f}\right) \frac{\partial T_{m}}{\partial t}\right] d \Omega+ \\
\int_{\Gamma_{c}} \frac{k_{n}}{\mu_{f}} \frac{\partial p}{\partial \mathbf{n}_{c}} d \Gamma
\end{gathered}
$$

Heat transfer through matrix:

$$
\begin{gathered}
\int_{\Omega} \operatorname{div}\left(\boldsymbol{\lambda}_{m} \nabla T_{m}\right) d \Omega=\int_{\Omega}\left[\left(\rho_{m} C_{m}-\beta_{s}{ }^{2} K T_{m}\right) \frac{\partial T_{m}}{\partial t}-\left(\alpha \beta_{s}+\phi \beta_{f}\right) T_{m} \frac{\partial p_{m}}{\partial t}+\right. \\
\left.\rho_{m} C_{m} \mathbf{v}_{m} \nabla T_{m}\right] d \Omega+\int_{\Gamma_{c}}\left[\lambda_{n} \frac{\partial T}{\partial \mathbf{n}_{c}}+\rho_{f} C_{f} \frac{k_{n}}{\mu_{f}} \frac{\partial p}{\partial \mathbf{n}_{c}}\left(T_{m}-T_{f}\right)\right] d \Gamma
\end{gathered}
$$

Fluid flow through fracture:

$$
\operatorname{div}\left(\frac{a_{f}^{3}}{12 \mu_{f}} \nabla p_{f}\right)=\left(\frac{1}{K_{n}}+a_{f} c_{f}\right) \frac{\partial p_{f}}{\partial t}-a_{f} \beta_{f} \frac{\partial T_{f}}{\partial t}-\frac{k_{n}}{\mu_{f}} \frac{\partial p}{\partial \mathbf{n}_{c}}
$$

Heat transfer through fracture:

$$
\begin{aligned}
& \operatorname{div}\left(a_{f} \lambda_{f} \nabla T_{f}\right)= \\
& \qquad a_{f} \rho_{f} C_{f} \frac{\partial T_{f}}{\partial t}-a_{f} \beta_{f} T_{f} \frac{\partial p_{f}}{\partial t}+a_{f} \rho_{f} C_{f} \mathbf{v}_{f} \cdot \nabla T_{f}-\lambda_{n} \frac{\partial T}{\partial \mathbf{n}_{c}}+\rho_{f} C_{f} \frac{k_{n}}{\mu_{f}} \frac{\partial p}{\partial \mathbf{n}_{c}}\left(T_{f}-T_{m}\right)
\end{aligned}
$$

\subsection{Finite Element Approximation}

The governing equations 15 to 19 are solved numerically using the finite element method. The Galerkin method and finite difference techniques are used for spatial and temporal discretisation, respectively. The displacement vector $\mathbf{u}$ is defined as the primary variable in the mechanical contact model, whereas the fluid pressures, $p_{m}$ and $p_{f}$, and matrix and fracture fluid temperatures, $T_{m}$ and $T_{f}$, are defined as the primary variables in the TH 
model. Using the standard Galerkin method, the primary variable $\mathbb{X}$ within an element is approximated from its nodal values as

$$
\mathbb{X}=\mathbf{N} \widehat{\mathbb{X}}
$$

where $\mathbf{N}$ is the vector of shape functions, and $\widehat{\mathbb{X}}$ is the vector of nodal values. Using the finite difference technique, the time derivative of $\mathbb{X}$ is defined as

$$
\frac{\partial \mathbb{X}}{\partial t}=\frac{\mathbb{X}^{t+d t}-\mathbb{X}^{t}}{d t}
$$

where $\mathbb{X}^{t+d t}$ and $\mathbb{X}^{t}$ are the values of $\mathbb{X}$ at time $t+d t$ and $t$, respectively. The set of discretised equations can be written in matrix form as $\mathbb{S X}=\mathbb{F}$, in which $\mathbb{S}$ is the element's general stiffness matrix, and $\mathbb{F}$ is the vector of right-hand-side loadings. The discretised equations are implemented in the Complex Systems Modelling Platform (CSMP++, also known as CSP), an object-oriented application programme interface (API), for the simulation of complex geological processes and their interactions (formerly CSP, cf. Matthäi et al., 2001). Quadratic unstructured elements are used for spatial discretisation of surfaces (quadratic triangles) and volumes (quadratic tetrahedra). The triangles on two opposite surfaces of a fracture are matched with each other, but do not share nodes, and duplicate nodes are defined for two sides of a fracture. The triangles are matched with faces of the tetrahedra connected to the fractures, and they share the same nodes. Fracture flow and heat equations are solved only on one-side of the fracture, whereas, the matrix deformation, fluid flow and heat transfer equations are accumulated over the volume elements. The ensuing set of linear algebraic equations $\mathbb{S X}=\mathbb{F}$ is solved at each timestep using the algebraic multigrid method for systems, SAMG (Stüben, 2001).

\subsection{Mechanical Contact Model}

In the present study, fractures are modelled as surface discontinuities within a threedimensional matrix; therefore, the contact problem arises and the contact stresses (normal and shear) need to be computed in order to avoid the penetration of the fracture surfaces into the opposite matrix, under compressive loading. The Augmented Lagrangian (AL) method has been successful for accurately enforcing the contact constraint, by combining the Lagrange multiplier and penalty methods to exploit the merits of both approaches (Wriggers and Zavarise, 1993; Puso and Laursen, 2004). A sophisticated algorithm is used for the treatment of frictional contact between the fracture surfaces, based on isoparametric integration-pointto-integration-point discretisation of the contact contribution. Contact constraints are enforced by using a gap-based AL method developed specifically for fractured media (Nejati et al., 2016). In this model, penalties are defined at each timestep as a function of local aperture, so that they are larger away from the fracture tips, and decrease to zero at the tips.

The mechanical contact (M) and TH models are coupled iteratively, such that in each timestep, the TH model is run using the fracture apertures computed in the previous step, and 
the new nodal values of pressures and temperatures are computed. Then, the contact model is run with new pressures and temperatures, and the contact stresses and fracture apertures are updated. The contact model is run in the "stick" mode, which means that sliding along the opposing fracture surfaces is not allowed.

\section{Simulation of a Low-Permeability Geothermal System}

The proposed model has been previously validated against several analytical solutions and sets of experimental data, including hydraulic fracturing examples in the viscosity, toughness and leakoff regimes (Salimzadeh et al., $2017 \mathrm{a}, \mathrm{b}$ ), heat propagation from a single fracture (Salimzadeh et al., 2017c), and double-notch crack propagation experiments (Usui et $a l .$, 2017). The example used in this study is adopted from Guo et al. (2016), and the present model results are also validated against their results. In this example, heat is produced from a horizontal penny-shaped fracture in a low-permeability hot crystalline rock, which roughly resembles the Habanero project in the Cooper Basin, Australia (Chopra and Wyborn, 2003; Baisch et al., 2009; Llanos et al., 2015). The geometry consists of a fracture with radius of $500 \mathrm{~m}$, in the centre of a $3 \times 3 \times 3 \mathrm{~km}$ cubic block. The injection and production wells intersect the fracture, and are located $500 \mathrm{~m}$ apart, as shown in Figure 1. The initial pressure and temperature are set to $34 \mathrm{MPa}$ and $200^{\circ} \mathrm{C}$, respectively. Injection is simulated through a constant rate of $0.0125 \mathrm{~m}^{3} / \mathrm{s}$ of water at a temperature of $50^{\circ} \mathrm{C}$, while production is simulated through a constant pressure of $34 \mathrm{MPa}$ at the producer. The rock and fluid properties are given in Table 1. The fluid density is considered to be pressure- and temperature-dependant, using the following function:

$$
\rho_{f}=\rho_{r} e^{\left[\beta_{f}\left(p_{f}-p_{r}\right)-\alpha_{f}\left(T_{f}-T_{r}\right)\right]}
$$

where $\rho_{r}=887.2 \mathrm{~kg} / \mathrm{m}^{3}, p_{r}=34 \mathrm{MPa}$, and $T_{r}=200^{\circ} \mathrm{C}$ are the reference (initial) density, pressure and temperature, respectively. The fracture aperture is defined as a function of the contact stress, using the Barton-Bandis model. Two reference points are assumed to evaluate the model parameters $a$ and $b$, where the fracture aperture at zero contact stress $a_{0}$ is assumed equal to $a / b$. The two reference points are: $a_{f}=0.24 \mathrm{~mm}$ for $\sigma_{n}=30 \mathrm{MPa}$, and $a_{f}=0.72 \mathrm{~mm}$ for $\sigma_{n}=5 \mathrm{MPa}$. For these given data, the model parameters $a$ and $b$ are $1.6 \times 10^{-10} / \mathrm{Pa}$ and $1.333 \times 10^{-7} / \mathrm{Pa}$, respectively, and the aperture function takes the form of

$$
a_{f}=0.0012-\frac{1.6 \times 10^{-10} \sigma_{n}}{1+1.333 \times 10^{-7} \sigma_{n}}
$$

The domain is discretised spatially using 39,957 quadratic tetrahedra and triangles for the matrix volume and fracture surface, respectively. Several cases are simulated for the injection of cold water, for a duration of thirty years, and the results are presented and discussed in the following subsections. 


\subsection{The Effect of Matrix Permeability}

The rock matrix permeability in enhanced geothermal systems (EGS) usually is very low, ranging from micro-Darcies $\left(10^{-18} \mathrm{~m}^{2}\right)$ to nano-Darcies $\left(10^{-21} \mathrm{~m}^{2}\right)$. Therefore, fluid flow through the matrix is frequently ignored in the numerical simulations, and the heat transfer through the matrix is assumed to occur only through conduction (Zhao et al., 2015; Sun et al., 2017). The average values for matrix thermal conductivity $\left(\boldsymbol{\lambda}_{m}\right)$, density $\left(\rho_{m}\right)$ and heat capacity $\left(C_{m}\right)$ are calculated from arithmetic average of the corresponding values for the rock solid $\left(\boldsymbol{\lambda}_{s}, \rho_{s}, C_{s}\right)$ and the fluid $\left(\boldsymbol{\lambda}_{f}, \rho_{f}, C_{f}\right)$ as

$$
\begin{array}{r}
\boldsymbol{\lambda}_{m}=(1-\phi) \boldsymbol{\lambda}_{s}+\phi \boldsymbol{\lambda}_{f} \\
\rho_{m} C_{m}=(1-\phi) \rho_{s} C_{s}+\phi \rho_{f} C_{f}
\end{array}
$$

More accurate models of the effective thermal conductivity can also be used (Zimmerman, 1989). The volumetric matrix thermal expansion coefficient of the solid $\left(\beta_{s}\right)$ is modified for a low permeability matrix using the expression given by McTigue (1986), for undrained thermal expansion of a rock-fluid system:

$$
\beta_{u}=\beta_{s}+\phi B\left(\beta_{f}-\beta_{s}\right)
$$

where $\beta_{u}$ is the effective thermal expansion coefficient of a fluid-saturated rock under undrained conditions, and $B$ is the Skempton coefficient (Jaeger et al., 2007). Similar expressions for the undrained thermal expansion coefficient can be extracted from the governing equations given in this study. Under undrained conditions, the increment in the fluid pressure in the matrix due to an increment in the temperature, in the absence of leakoff, can be computed from the governing equation for the flow through matrix (Eq. 16) as

$$
\Delta p_{m}=\frac{\phi\left(\beta_{f}-\beta_{s}\right)}{\frac{\alpha^{2}}{K}+\phi c_{f}+\frac{\alpha-\phi}{K_{s}}} \Delta T_{m}
$$

Then, the increment in the volumetric strain of the matrix due to an increment in the temperature can be computed from Eq. (11) as

$$
\Delta \varepsilon_{v}=\left[\beta_{s}+\frac{\alpha \phi\left(\beta_{f}-\beta_{s}\right)}{\alpha^{2}+K \phi c_{f}+(\alpha-\phi)(1-\alpha)}\right] \Delta T_{m}
$$

and the equivalent thermal expansion coefficient $\left(\beta_{e q}\right)$ can be written as

$$
\beta_{e q}=\beta_{s}+\frac{\alpha \phi\left(\beta_{f}-\beta_{s}\right)}{\alpha^{2}+K \phi c_{f}+(\alpha-\phi)(1-\alpha)}
$$

and by setting $\beta_{e q}=\beta_{u}$, the coefficient $B$ can be evaluated as

$$
B=\frac{\alpha}{\alpha^{2}+K \phi c_{f}+(\alpha-\phi)(1-\alpha)}
$$

For the given bulk modulus, porosity, and fluid compressibility used in this example, the undrained volumetric thermal expansion, assuming $\alpha=1$, is $\beta_{u}=3.0 \times 10^{-5} /{ }^{\circ} \mathrm{C}$. Although the rock has a very low porosity $(\phi=0.01)$, the undrained thermal expansion coefficient is 
nevertheless $25 \%$ greater than the rock volumetric thermal expansion. This is due to the fact that water has a much higher thermal expansion coefficient than the rock (by a factor of about thirty). Using the undrained thermal expansion coefficient, a good match is found between the present model results for the fluid temperature at the producer versus time, and the results given by Guo et al. (2016) for the case of a homogeneous initial aperture, as shown in Figure 2. The good match validates our simulator, as well as the mesh used in the present model. Included in this figure is also the case with drained volumetric thermal expansion coefficient (i.e., equivalent to that of rock solid, $\beta_{s}$ ). Using the drained thermal expansion coefficient for the matrix reduces the temperature drop at the producer, such that the breakthrough time for water with a temperature of $130^{\circ} \mathrm{C}$, for instance, extends from less than 21 years for the undrained case, to 27.6 years for the drained case. Lower thermal expansion results in lower volumetric contraction of the matrix, and as a result, a smaller increase in the fracture aperture during the heat extraction from the reservoir. The variation of the fracture aperture at the injection point versus time is shown in Figure 2.

Although neglecting fluid flow through the matrix may reduce the computational effort, selection of the volumetric thermal expansion coefficient (whether it is under drained or undrained conditions) can significantly affect the outcome of the simulation. To investigate the flow regime in the matrix, several cases with varying matrix permeability have been simulated. The matrix permeability ranges between $10^{-17} \mathrm{~m}^{2}$ to $10^{-22} \mathrm{~m}^{2}$, corresponding to the range of rock permeabilities observed in the majority of EGS projects, while the drained volumetric thermal expansion coefficient (i.e., equivalent to that of rock solid, $\beta_{s}$ ) is used for matrix. The results for the fluid temperature at the production well, and the fracture aperture at the injection well, for these cases are also presented in Figure 2. Fluid leakoff from the fracture into the matrix can be assumed to be negligible, due to the very low permeability of the matrix, except for the cases with permeabilities of $10^{-17} \mathrm{~m}^{2}$ and $10^{-18} \mathrm{~m}^{2}$. In the presence of fluid leakoff, the heat extraction from the matrix significantly improves, which in turn delays the cold-water production at the producer (Ghassemi et al., 2011; Salimzadeh et al., 2017c). Furthermore, the leakoff flow increases the fluid pressure in the matrix, leading to expansion of the matrix and development of a so-called back-stress (Salimzadeh et al., 2017a, b). The back-stress closes the fracture, and reduces the fracture aperture, as can be seen in Figure 2 for cases with permeability of $10^{-17} \mathrm{~m}^{2}$ and $10^{-18} \mathrm{~m}^{2}$. In other low-permeability cases, the variation in the results is primarily due to the variation in fluid pressure trapped in the matrix pores. As heat propagates through the matrix, the temperature in the matrix decreases, the rock and the fluid constituents undergo volumetric contractions, but as the fluid thermal expansion is much higher than that of the rock, the volume change in the fluid constituent is much higher than change in the pore volume. Therefore, the fluid pressure changes in response to the constraint imposed by the relatively stiffer pore volume. As the permeability decreases, the condition for the fluid in the matrix 
approaches undrained conditions, and the results for both fluid temperature at the production well, and the fracture aperture at the injection point, approach the undrained solution. The case with matrix permeability $k_{m}=10^{-22} \mathrm{~m}^{2}$ shows a good match to the undrained results, both for the fluid temperature at the production well, and the fracture aperture in the injection point, as shown in Figure 2.

The matrix pressure distribution at the end of the simulations (30 years), on a vertical cut-plane passing through the injection and production points, is shown in Figure 3 . For the two high permeability cases $\left(k_{m}=10^{-17} \mathrm{~m}^{2}\right.$ and $10^{-18} \mathrm{~m}^{2}$ ), fluid leakoff occurs, and so the fluid pressure in the matrix increases, with the highest pressure at the fracture. As the matrix permeability decreases, the rate of fluid diffusion reduces, and the region with increased fluid pressure shrinks. For cases with matrix permeability less than $k_{m}=10^{-18} \mathrm{~m}^{2}$, a region with reduces fluid pressure develops, and the magnitude of the depleted pressure increases with reduction in the matrix permeability. The low-pressure region is located close to the fracture, and shows the region affected by the cooling of the matrix (Figure 4), and is not drained. The pressure depletion is a result of cooling of the matrix. The distribution of matrix temperature on the same vertical plane after 30 years for different cases is shown in Figure 4 . It can be seen that the variation in the permeability of the matrix has a small effect on the temperature distribution, confirming that heat transfer in the matrix is mainly conductive. Furthermore, heat transfer in the matrix is mainly one-dimensional, except for the edges of the temperature plume. The aperture distributions on the fracture for different cases at the end of the simulations are shown in Figure 5. Thermoporoelastic stresses develop higher fracture apertures in the vicinity of the injection point. The region with increased aperture points towards the producer. As the permeability of the matrix decreases, the pressure depletion due to cooling of the matrix increases, which leads to more contraction of the deformable matrix, and an increased aperture. The increased aperture facilitates fluid flow towards the producer, resulting in lower heat extraction rate from the system, and faster temperature reduction at the producer. The maximum aperture occurs not at the injection point, but at a point behind the injection well, away from the production point and towards the fracture tip. This is due to the stress redistribution over the fracture and surrounding matrix.

The vertical effective stress distribution on a horizontal plane passing through the fracture, for the case with $k_{m}=10^{-20} \mathrm{~m}^{2}$, is shown in Figure 6 . The cooling of the matrix reduces the vertical effective stress over the parts of the fracture that contain cold flowing fluid. This results in an increased vertical stress on the vicinity of the cooled area, as can be seen in Figure 6. The region with increased stress extends beyond the fracture and over the rock matrix on the left side of the injection point (away from the production point). Therefore, the location of the minimum vertical stress, i.e., maximum aperture, moves towards the left side of the injection well. 
The results of the present model show that the matrix permeability used in this example, $k_{m}=10^{-20} \mathrm{~m}^{2}$, does not allow the persistence of undrained conditions, and the results for this value of matrix permeability are actually closer to those which occur under drained conditions. This is due to the relatively slow diffusion process of heat in the matrix. For a one-dimensional diffusive process in a column of height $h$, the time needed for completion of the process can be defined in terms of dimensionless time $\left(t_{D}\right)$ as (Carslaw and Jaeger, 1959)

$$
t_{D}=\frac{\alpha_{D} t}{h^{2}}
$$

in which $\alpha_{D}$ is the diffusion coefficient, and $t$ is elapsed time. A value of $t_{D}=0.001$ corresponds to $3 \%$ completion of the process and $t_{D}=1.0$ corresponds to $94 \%$ completion of the diffusive process (Carslaw and Jaeger, 1959). So, for developing undrained conditions, for a given time, the dimensionless time of the hydraulic diffusion $\left(t_{D h}\right)$ should be significantly smaller than the dimensionless time of the heat diffusion process $\left(t_{D T}\right)$. Assuming $t_{D h} \leq 0.01 t_{D T}$ for undrained behaviour, the hydraulic and thermal diffusion coefficients are related by

$$
\alpha_{D h} \leq 0.01 \alpha_{D T}
$$

where $\alpha_{D h}=k_{m} / \mu c_{t}$ and $\alpha_{D T}=\lambda_{m} / \rho_{m} C_{m}$ are the hydraulic and thermal diffusion coefficients, respectively, and $c_{t}=\alpha^{2} / K+\phi c_{f}+(\alpha-\phi) / K_{s}$ is the total compressibility of the fluid-saturated matrix. Using the given parameters in the example, and setting $\alpha=1$, the matrix permeability should be smaller than

$$
k_{m} \leq 8.43 \times 10^{-23} \mathrm{~m}^{2}
$$

Thus, in order to satisfy the conditions of undrained behaviour, the matrix permeability should be less than $8.43 \times 10^{-23} \mathrm{~m}^{2}$, whereas the given value of $k_{m}=10^{-20} \mathrm{~m}^{2}$ in the example results in $t_{D p}=1.2 t_{D h}$, in which case the assumption of undrained behaviour is not acceptable.

\subsection{The Effects of Poroelastic Coupling and Matrix Porosity}

The Skempton coefficient $B$, as given by Eq. (30), is dependent on several parameters, including the Biot coefficient of poroelasticity $(\alpha)$ and matrix porosity $(\phi)$. Matrix porosity also influences the contribution of the fluid constituent to the thermal properties of the saturated rock. In this section, further simulations are run with varied Biot coefficients and matrix porosities, to investigate the effect of these two parameters on the response of the lowpermeability saturated rock to the temperature perturbation during heat extraction from the example of the EGS project.

The Biot coefficient can never be less than $3 \phi /(2+\phi)$ (Zimmerman, 2000), and generally decreases with a decrease in matrix porosity (Tan and Konietzky, 2017). In the next 
set of simulations, the Biot coefficient is reduced to $\alpha=0.2$, which is more realistic for granite having a very low porosity. The results for temperature at the producing well versus time, as well as the fracture aperture at the injection well versus time, are shown in Figure 7. The lower Biot coefficient reduces the volumetric contraction due to the change in matrix pressure, and so the fracture aperture decreases as the Biot coefficient decreases, and hot fluid is produced for an extended period of time. The undrained volumetric thermal expansion coefficient is also reduced to $\beta_{u}=2.81 \times 10^{-5} /{ }^{\circ} \mathrm{C}$ for $\alpha=0.2$, and the results for the temperature at the production well, and the fracture aperture at the injection point, for the drained and undrained cases, are also shown in Figure 7. The results for the undrained case move closer to those for the drained case; however, there is still a large gap between the two behaviours. For instance, the temperature of the fluid at the producer reaches $130^{\circ} \mathrm{C}$ in about 22.4 years, whereas in the drained case this requires 27.6 years, and for the case of $k_{m}=10^{-20}$ $\mathrm{m}^{2}$ it requires 26.1 years. To satisfy the condition for undrained behaviour, as defined earlier, $\alpha_{D h} \leq 0.01 \alpha_{D T}$, the matrix permeability should be smaller than $2.6 \times 10^{-23} \mathrm{~m}^{2}$, which is smaller than the corresponding critical value when $\alpha=1.0$. So, for low values of the Biot coefficient, the condition of the fluid in the matrix is much closer to the drained condition than to undrained condition, for the given permeability.

In another simulation case, the porosity of the matrix has been increased to $\phi=0.10$, while the Biot coefficient is set to $\alpha=0.2$. The results for the fluid temperature at the producer versus time, and the fracture aperture at the injection point versus time, are shown in Figure 8. The higher porosity increases the contribution of the fluid thermal expansion coefficient in the undrained thermal expansion coefficient, as shown in Eq. (26). As the thermal expansion coefficient of the fluid is much higher than that of the rock, the undrained thermal expansion coefficient becomes larger for larger porosity, i.e. $\beta_{u}=3.21 \times 10^{-5} /{ }^{\circ} \mathrm{C}$ for $\phi$ $=0.1$. The average heat storage $\left(\rho_{m} C_{m}\right)$ also increases, from $2.05 \times 10^{6} \mathrm{~J} / \mathrm{m}^{3 \circ} \mathrm{C}$ to $2.72 \times 10^{6}$ $\mathrm{J} / \mathrm{m}^{3 \circ} \mathrm{C}$, when the porosity increases from 0.01 to 0.1 . This is due to the higher heat storage of the fluid $\left(\rho_{f} C_{f}\right)$ compared to that of the rock $\left(\rho_{s} C_{s}\right)$. Thus, under drained conditions, the matrix experiences lower temperature reduction, lower matrix contraction, and higher heat production at the producer. In undrained conditions, the elevated volumetric thermal expansion dominates the results, matrix contraction increases, the fracture aperture increases, and the temperature of the produced water decreases faster than in the case with lower porosity. As a result, the gap between the drained and undrained solutions increases, such that the temperature of the produced water reaches $130^{\circ} \mathrm{C}$ in 20.6 years for the undrained case, compared to 28.6 years for the drained case, and 25.4 years for the case with a permeability $k_{m}=10^{-20} \mathrm{~m}^{2}$. Again, to satisfy the condition for undrained behaviour, $\alpha_{D h} \leq \alpha_{D T}$, the matrix permeability would need to be smaller than $9.2 \times 10^{-23} \mathrm{~m}^{2}$. 


\subsection{Thermal Expansion Coefficient for Partially-Drained Matrix}

The thermal diffusion coefficient of rocks ranges between $\alpha_{D T}=5 \times 10^{-7} \mathrm{~m}^{2} / \mathrm{s}$ to $11 \times 10^{-}$ ${ }^{7} \mathrm{~m}^{2} / \mathrm{s}$ (Jaeger et al., 2007). While the thermal diffusion coefficient for different rocks does not vary widely, the hydraulic diffusion coefficient for low-permeability rocks $\left(k_{m}=1 \times 10^{-18}\right.$ $\mathrm{m}^{2}$ to $\left.1 \times 10^{-21} \mathrm{~m}^{2}\right)$ saturated with water $\left(\mu=1 \times 10^{-3} \mathrm{~m}^{2} / \mathrm{s}\right.$ to $\left.1 \times 10^{-4} \mathrm{~Pa} \mathrm{~s}\right)$ can vary by several orders of magnitude, from $\alpha_{D T}=1 \times 10^{-8} \mathrm{~m}^{2} / \mathrm{s}$ to $1 \times 10^{-4} \mathrm{~m}^{2} / \mathrm{s}$. Thus, hydraulic diffusivity can in some cases be comparable to thermal diffusivity, and so a fully undrained behaviour $\left(\alpha_{D h} / \alpha_{D T}<0.001-0.01\right)$ is not expected, for most EGS projects. The flow condition is in fact expected to be somewhere between the drained and undrained conditions, i.e., partially drained condition.

As the full thermoporoelastic simulations are computationally expensive, it would be convenient if simulations could be conducted without using the full thermoporoelastic model, but with an "effective" thermal expansion coefficient that accounts for the effect of "partial drainage". From the simulation results presented earlier in this study, a degree of drainage can be quantified using the fracture aperture at the injection point at the end of the simulation, as follows:

$$
\delta_{D}=\frac{a_{f}-a_{f D}}{a_{f U}-a_{f D}}
$$

where $a_{f D}$ is the fracture aperture calculated using the drained thermal expansion coefficient, and $a_{f U}$ is the fracture aperture calculated using the undrained thermal expansion coefficient. The values for $\delta_{D}$ are plotted versus the non-dimensional diffusion ratio $\xi_{D}=1-$ $\log \left(\alpha_{D h} / \alpha_{D T}\right)$ in Figure 9. Only positive values for $\delta_{D}$ are considered, as negative values are assumed to be representative of leakoff. Thus, the value of $\delta_{D}$ varies between 0 for a fully drained situation, to 1 for a fully undrained situation. The data plotted in Figure 9 show a linear correlation between the dimensionless diffusion ratio and dimensionless drainage ratio. To validate this relationship, a test case was built using a new set of parameters: $\phi=0.05, \alpha=$ $0.40, k_{m}=2 \times 10^{-21} \mathrm{~m}^{2}$. The corresponding values for hydraulic and thermal diffusion coefficients are $\alpha_{D h}=3.87 \times 10^{-7} \mathrm{~m}^{2} / \mathrm{s}$, and $\alpha_{D T}=1.42 \times 10^{-6} \mathrm{~m}^{2} / \mathrm{s}$, respectively, and the dimensionless diffusion ratio is $\xi_{D}=1.568$. Using the linear correlation given in Figure 9, the dimensionless drainage ratio is calculated as $\delta_{D}=0.509$. The dimensionless drainage ratio is used to modify the undrained thermal expansion coefficient as

$$
\beta_{e q}=\beta_{s}+\delta_{D} \phi B\left(\beta_{f}-\beta_{s}\right)
$$

such that $\beta_{e q}=\beta_{s}$ if $\delta_{D}=0$, and $\beta_{e q}=\beta_{u}$ if $\delta_{D}=1$. For the given parameters, the undrained thermal expansion coefficient is $\beta_{u}=3.62 \times 10^{-5} /{ }^{\circ} \mathrm{C}$, the equivalent thermal expansion coefficient for $\delta_{D}=0.509$ is $\beta_{e q}=3.02 \times 10^{-5} /{ }^{\circ} \mathrm{C}$, and the drained thermal expansion coefficient is $\beta_{s}=2.40 \times 10^{-5} /{ }^{\circ} \mathrm{C}$, which is equal to the rock volumetric expansion coefficient. The results for the fluid temperature at the producer as well as the fracture aperture at the injection point versus time are shown in Figure 10 for the drained, undrained, and semi-drained cases. The 
results show that the case with a modified thermal expansion coefficient $\left(\beta_{e q}\right)$ provides a better prediction of the actual results from the thermoporoelastic model (full model), compared to both other cases, with drained or undrained thermal expansion coefficients. Also, the calculated dimensionless drainage ratio for the test case (full thermoporoelastic model) computed from the fracture aperture at the injection point at time $t=30$ years is $\delta_{D}=$ 0.507 , which is almost equal to the predicted value from the linear correlation $\left(\delta_{D}=0.509\right)$, which is shown with a blue circle in Figure 9. The case with a modified thermal expansion coefficient $\left(\beta_{e q}\right)$, however, cannot exactly capture the full thermoporoelastic model, as shown with a red cross $(x)$ in Figure 9. The reason is that the dimensionless drainage ratio is not constant, but varies during the simulation, decreasing as time elapses. Therefore, the drainage ratio calculated from the results at $t=30$ years is lower than the average value during the 30 years, and as such the predicted aperture is lower than that predicted by the full thermoporoelastic model.

\section{Conclusions}

A coupled thermo-hydraulic (TH) model that accounts for the mechanical deformation of the matrix has been presented. The TH model is coupled to a rigorous mechanical contact model that solves for the contact tractions on fracture surfaces under compressive thermoporoelastic compression. The model has been applied to investigate the effect of thermoporoelasticity during heat extraction from a low-permeability fractured geothermal reservoir. The results show that the assumption of undrained conditions for the fluid trapped in the low-permeability matrix may not be accurate, due to the low thermal diffusivity of the matrix. The thermal diffusion coefficient could be as small as the hydraulic one, in which case the fluid is partially drained. This is important, as the fluid usually has a relatively higher thermal expansion coefficient than the rock, so the undrained thermal expansion coefficient is higher than the drained thermal expansion coefficient. As a result, assuming undrained conditions for the saturated low-permeability matrix in EGS projects may overestimate the volumetric contraction of the matrix, whereas using a drained thermal expansion coefficient may underestimate the volumetric contraction of the matrix. An "equivalent" thermal expansion coefficient can be calculated from the drained and undrained coefficients that can be used to make a better prediction of the poroelastic effect of the partially-drained matrix.

\section{Acknowledgments}

The first and second authors would like to thank the European Union for partially funding this work through European Union's Horizon 2020 research and innovation programme under grant agreement No 654662. 


\section{References}

Baisch, S., Vörös, R., Weidler, R., Wyborn, D., 2009. Investigation of fault mechanisms during geothermal reservoir stimulation experiments in the Cooper Basin, Australia. Bull. Seismol. Soc. Am. 99 (1), 148-158.

Bandis, S.C., Lumsden, A.C., Barton, N.R., 1983. Fundamentals of rock joint deformation. Int. J. Rock Mech. Min. Sci. 20 (6), 249-268.

Barton, N., Bandis, S., Bakhtar, K., 1986. Strength, deformation and conductivity coupling of rock joints. Int. J. Rock Mech. Min. Sci. 22 (3), 121-140.

Bellarby, J. 2009. Well completion design. Developments in Petroleum Science, 56. Elsevier, Amsterdam.

Benson, S.M., Daggett J.S., Iglesias E., Arellano V., Ortiz-Ramirez J. 1987. Analysis of thermally induced permeability enhancement in geothermal injection wells. In Proceedings of the 12th Workshop on Geothermal Reservoir Engineering, Stanford University, Stanford, California, January 20-22, 1987, SGP-TR-1W.

Biot, M.A., 1941. A general theory of three-dimensional consolidation, J. Appl. Phys. 12, $155-164$.

Bisdom, K., Bertotti, G., Nick, H.M. 2016. The impact of different aperture distribution models and critical stress criteria on equivalent permeability in fractured rocks, $J$. Geophys. Res. (Solid Earth) 121(5), 4045-4063.

Carslaw H.S., Jaeger, J.C. 1959. Conduction of heat in solids, Clarendon Press, Oxford, UK.

Chopra, P., Wyborn, D., 2003. Australia's first hot dry rock geothermal energy extraction project is up and running in granite beneath the Cooper Basin, NE South Australia. Proceedings of the Ishihara Symposium: Granites and Associated Metallogenesis, 43.

Fu, P., Hao, Y., Walsh, S.D.C., Carrigan, C.R., 2015. Thermal drawdown-induced flow channeling in fractured geothermal reservoirs, Rock Mech. Rock Eng. 49(3), 1001-1024.

Ghassemi A., Zhou X. 2011. A three-dimensional thermo-poroelastic model for fracture response to injection/extraction in enhanced geothermal systems, Geothermics 40, 39-49. 
Guo B., Fu P., Hao Y., Peters C.A., Carrigan C.R. 2016. Thermal drawdown-induced flow channeling in a single fracture in EGS, Geothermics 61: 46-62.

Hicks, T.W., Pine, R.J., Willis-Richards, J., Xu, S., Jupe, A.J., Rodrigues, N.E.V., 1996. A hydro-thermo-mechanical numerical model for HDR geothermal reservoir evaluation. Int. J. Rock Mech. Min. Sci. 33 (5), 499-511.

Jaeger J.C., Cook N.G.W., Zimmerman R.W. 2007, Fundamentals of Rock Mechanics (4 ${ }^{\text {th }}$ edition), Blackwell Publishing, Oxford, UK.

Khalili, N., Selvadurai, A.P.S., 2003. A fully coupled constitutive model for thermo-hydromechanical analysis in elastic media with double porosity, Geophys. Res. Lett., 30(24), 2268, doi:10.1029/2003GL018838.

Khalili-Naghadeh, N., Valliappan, S. 1991, Flow through fissured porous media with deformable matrix: Implicit formulation, Water Resour. Res., 27(7), 1703-1709.

Koh, J., Roshan, H., Rahman, S.S., 2011. A numerical study on the long term thermoporoelastic effects of cold water injection into naturally fractured geothermal reservoirs. Comput. Geotech. 38 (5), 669-682.

Llanos, E.M., Zarrouk, S.J., Hogarth, R.A., 2015. Numerical model of the Habanero geothermal reservoir, Australia. Geothermics 53, 308-319.

Matthäi S.K., Geiger, S., Roberts, S.G. 2001. The complex systems platform csp3.0: Users guide. Technical report, ETH Zürich Research Reports.

McClure M.W., Horne R.N. 2014. An investigation of stimulation mechanisms in Enhanced Geothermal Systems, Int. J. Rock Mech. Min. Sci. 72: 242-260.

McDermott C.I., Randriamanjatosoa, A.R.L., Tenzer H., Kolditz, O. 2006. Simulation of heat extraction from crystalline rocks: The influence of coupled processes on differential reservoir cooling, Geothermics 35, 321-344.

McTigue, D. F. 1986. Thermoelastic response of fluid-saturated porous rock, J. Geophys. Res., 91, 9533-42. 
MIT Report: The future of geothermal energy: impact of enhanced geothermal systems (EGS) on the United States in the $21^{\text {st }}$ century. Massachusetts Institute of Technology, 2006.

Nejati, M., Paluszny, A., Zimmerman, R.W. 2016. A finite element framework for modelling internal frictional contact in three-dimensional fractured media using unstructured tetrahedral meshes, Comput. Methods Appl. Mech. Engrg. 306, 123-150.

Puso M., Laursen T. 2004. A mortar segment-to-segment contact method for large deformation solid mechanics, Comput. Methods Appl. Mech. Engrg. 193, 601-629.

Rutqvist, J., Barr, D., Datta, R., Gens, A., Millard, A., Olivella, S., Tsang, C.F., Tsang, Y., 2005. Coupled thermal-hydrological-mechanical analyses of the Yucca Mountain Drift Scale Test-Comparison of field measurements to predictions of four different numerical models. Int. J. Rock Mech. Min. Sci. 42 (5-6), 680-697.

Salimzadeh S., Khalili, N., 2015. A three-phase XFEM model for hydraulic fracturing with cohesive crack propagation, Comput. Geotech. 69, 82-92.

Salimzadeh S., Khalili, N., 2016. A fully coupled XFEM model for flow and deformation in fractured porous media with explicit fracture flow, Int. J. Geomech. 16, 04015091.

Salimzadeh S., Paluszny A., Zimmerman R.W. 2016. Thermal Effects during Hydraulic Fracturing in Low-Permeability Brittle Rocks, In Proceedings of the 50th US Rock Mechanics Symposium, Houston, Texas, 26-29 June 2016, paper ARMA 16-368.

Salimzadeh S., Paluszny A., Zimmerman R.W. 2017a. Three-dimensional poroelastic effects during hydraulic fracturing in permeable rocks, Int. J. Solids Struct. 108, 153-163.

Salimzadeh S., Paluszny A., Zimmerman R.W. 2017b. Finite Element Simulations of Interactions between Multiple Hydraulic Fractures in a Poroelastic Rock, Int. J. Rock Mech. Min. Sci. 99C (2017) pp. 9-20 DOI: 10.1016/j.ijrmms.2017.09.001.

Salimzadeh S., Paluszny A., Nick H.M., Zimmerman R.W. 2017c. A three-dimensional coupled thermo-hydro-mechanical model for deformable fractured geothermal systems, Geothermics (in press). 
Santarelli F.J., Havmoller O., Naumann M. 2008. Geomechanical aspects of 15 years water injection on a field complex: an analysis of the past to plan the future. Paper SPE $112944,15 p$.

Stüben, K. 2001. A review of algebraic multigrid. J. Comput. Appl. Math. 128: 281-309.

Sun, Z., Zhang, X., Xu, Y., Yao, J., Wang, H., Lv, S., Sun, Z., Huang, Y., Cai, M., Huang, X., 2017. Numerical simulation of the heat extraction in EGS with thermal-hydraulicmechanical coupling method based on discrete fractures model, Energy, 120 (1), 20-33.

Tan, X., Konietzky, H. 2017. Numerical study of Biot's coefficient evolution during failure process for Aue Granite using an empirical equation based on GMR method, Rock Mech Rock Eng. 50, 1683-1689.

Tsang, C.-F., 1991. Coupled hydromechanical-thermochemical processes in rock fractures. Rev. Geophys. 29 (4), 537-552.

Tulinius, H., Correia, H., Sigurdsson, O. 2000. Stimulating a high enthalpy well by thermal cracking. In Proceedings of the World Geothermal Congress, Kyushu - Tohoku, Japan, May 28 - June 10, 2000.

Usui T, Salimzadeh S, Paluszny A, Zimmerman RW. Effect of poroelasticity on hydraulic fracture interactions. In: Proceedings of the 6th Biot Conference on Poromechanics, Paris, France, 9-13 July 2017.

Wriggers P., Zavarise, G. 1993. Application of augmented lagrangian techniques for nonlinear constitutive laws in contact interfaces, Comm. Numer. Meth. Eng. 9(10), 815-824.

Wu B., G. Zhang, X. Zhang, R. G. Jeffrey, J. Kear, T. Zhao. 2017. Semi-analytical model for a geothermal system considering the effect of areal flow between dipole wells on heat extraction, Energy, 138, 2017, 290-305.

Zhao, Y., Feng, Z., Feng, Z., Yang, D., Liang, W. 2015. THM (Thermo-hydro-mechanical) coupled mathematical model of fractured media and numerical simulation of a 3D enhanced geothermal system at $573 \mathrm{~K}$ and buried depth 6000-7000 M, Energy, 82 (15), 193-205. 
Zimmerman, R.W. 1989. Thermal conductivity of fluid-saturated rocks. J. Petrol. Sci. Eng. 3, 219-227.

Zimmerman, R.W. 2000. Coupling in poroelasticity and thermoelasticity. Int. J. Rock Mech. Min. Sci. 37: 79-87.

Zimmerman, R.W., Bodvarsson, G.S. 1996. Hydraulic conductivity of rock fractures. Transp. Porous Media 23: 1-30. 
Table 1- The rock and fluid properties used in the simulations

\begin{tabular}{lll}
\hline Parameter & Value & Unit \\
\hline Matrix porosity $(\phi)$ & 0.01 & - \\
Matrix permeability $\left(k_{m}\right)$ & $1 \times 10^{-20}$ & $\mathrm{~m}^{2}$ \\
Solid density $\left(\rho_{s}\right)$ & 2500 & $\mathrm{~kg} / \mathrm{m}^{3}$ \\
Young's modulus $(E)$ & 50 & $\mathrm{GPa}$ \\
Poisson's ratio $(v)$ & 0.25 & - \\
Specific heat capacity of the solid $\left(C_{s}\right)$ & 790 & $\mathrm{~J} / \mathrm{kg}^{\circ} \mathrm{C}$ \\
Specific heat capacity of the fluid $\left(C_{f}\right)$ & 4460 & $\mathrm{~J} / \mathrm{kg}^{\circ} \mathrm{C}$ \\
Volumetric thermal expansion coefficient of the solid $\left(\beta_{s}\right)$ & $2.4 \times 10^{-5}$ & ${ }^{\circ} \mathrm{C}$ \\
Volumetric thermal expansion coefficient of the fluid $\left(\beta_{f}\right)$ & $7.66 \times 10^{-4}$ & ${ }^{\circ} \mathrm{C}$ \\
Fluid dynamic viscosity $\left(\mu_{f}\right)$ & $1.42 \times 10^{-4}$ & $\mathrm{~Pa} \mathrm{~s}$ \\
Fluid compressibility $\left(c_{f}\right)$ & $5.11 \times 10^{-10} \mathrm{~Pa}-1$ \\
Thermal conductivity of the solid $\left(\lambda_{s}\right)$ & 3.5 & $\mathrm{~W} / \mathrm{m}^{\circ} \mathrm{C}$ \\
Thermal conductivity of the fluid $\left(\lambda_{f}\right)$ & 0.6 & $\mathrm{~W} / \mathrm{m}^{\circ} \mathrm{C}$ \\
\hline
\end{tabular}



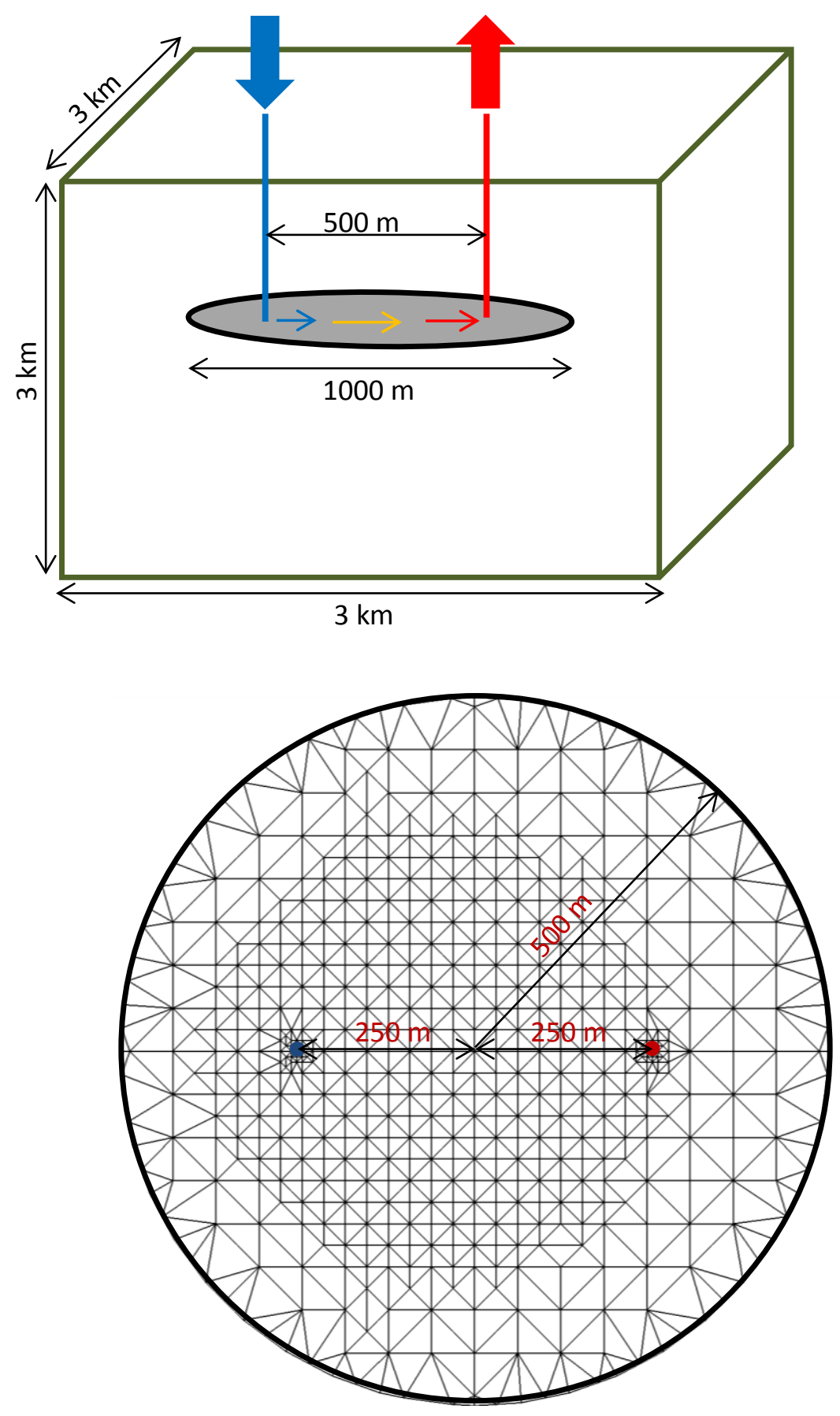

Figure 1. The geometry of the model for the EGS example and the mesh used for the fracture 

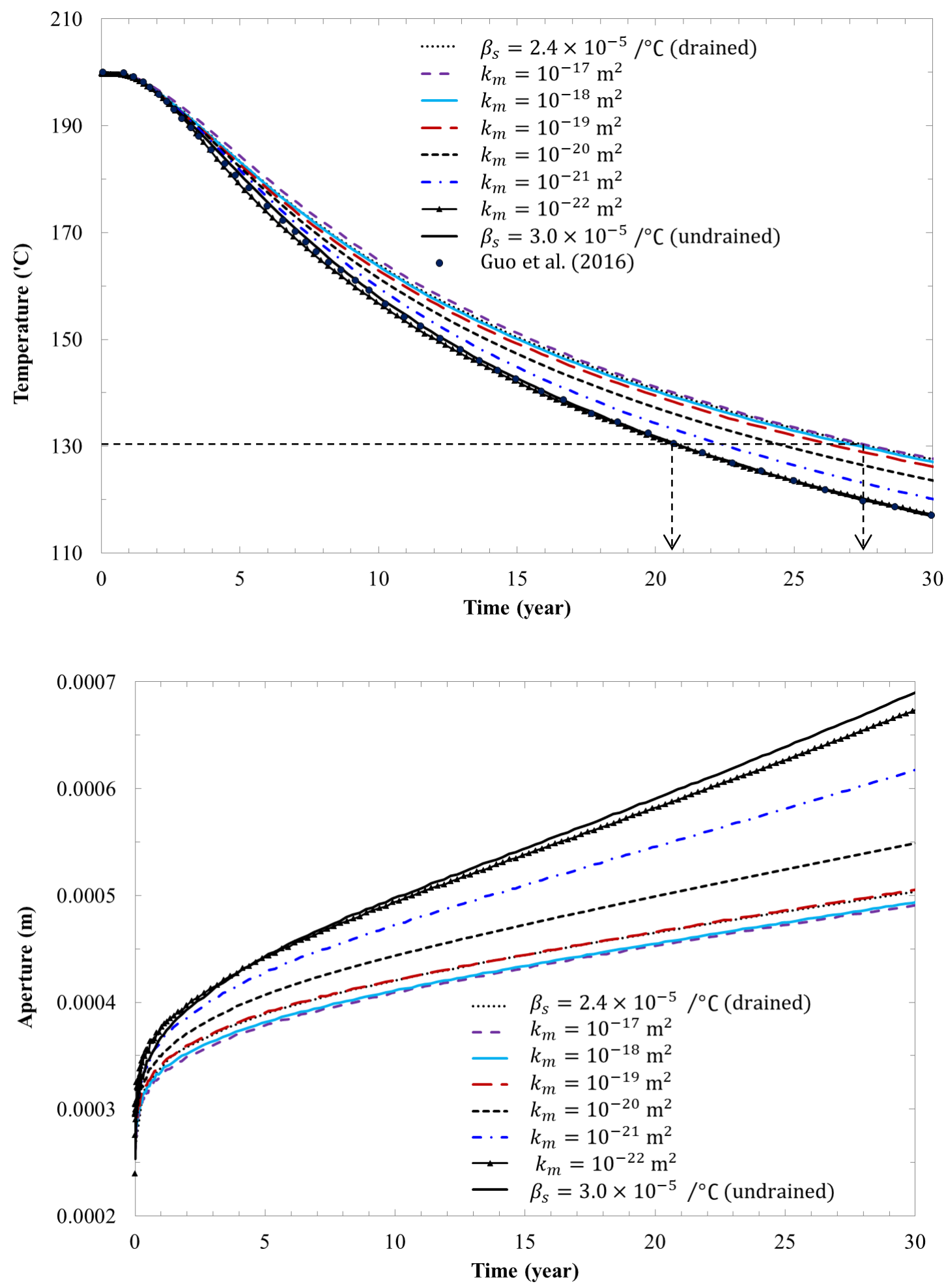

Figure 2. The fluid temperature at producer and the fracture aperture at injection point versus injection time for different matrix permeabilities 

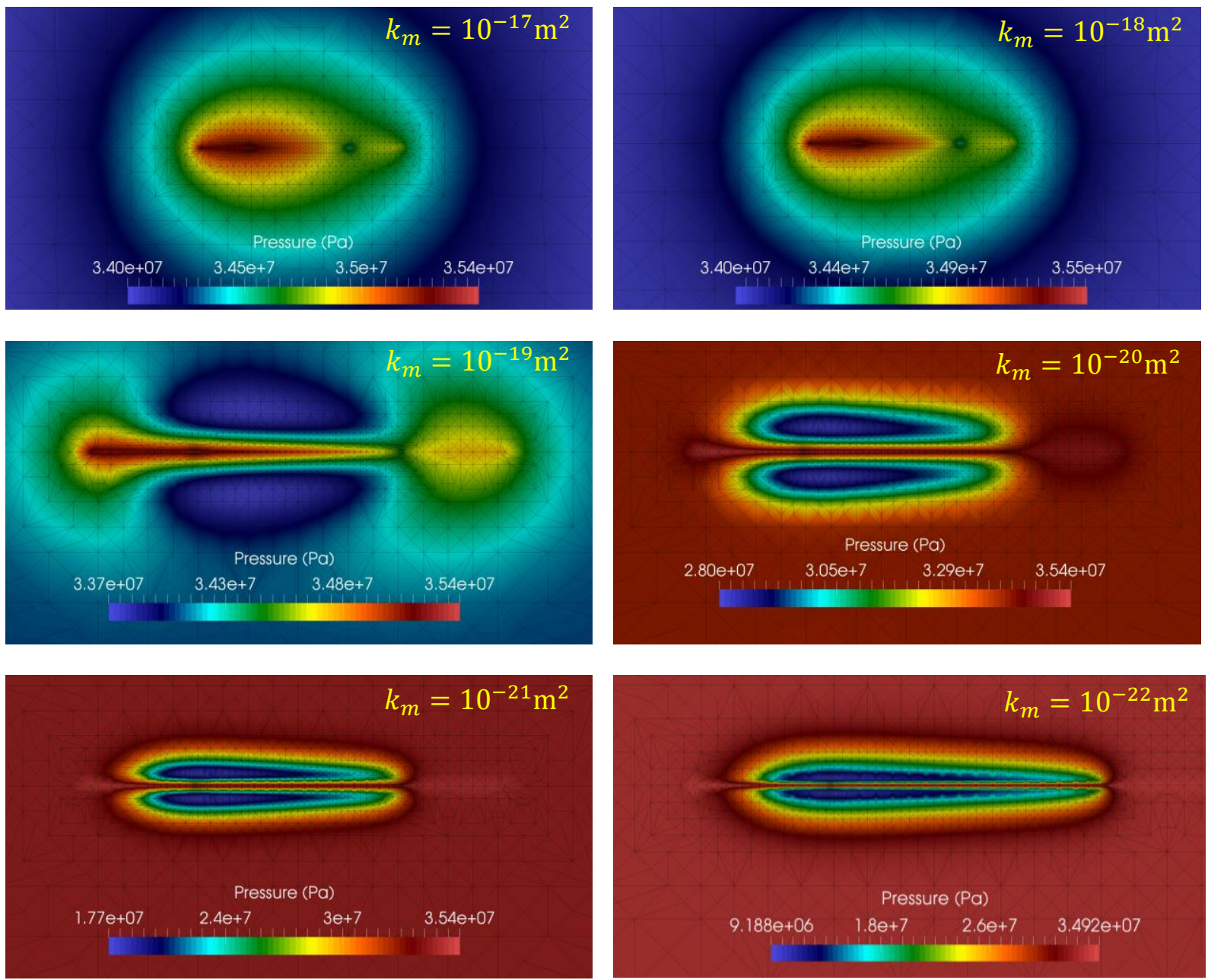

Figure 3. The fluid pressure distribution on a vertical plane passing through the injection and production points for different matrix permeabilities after 30 years 

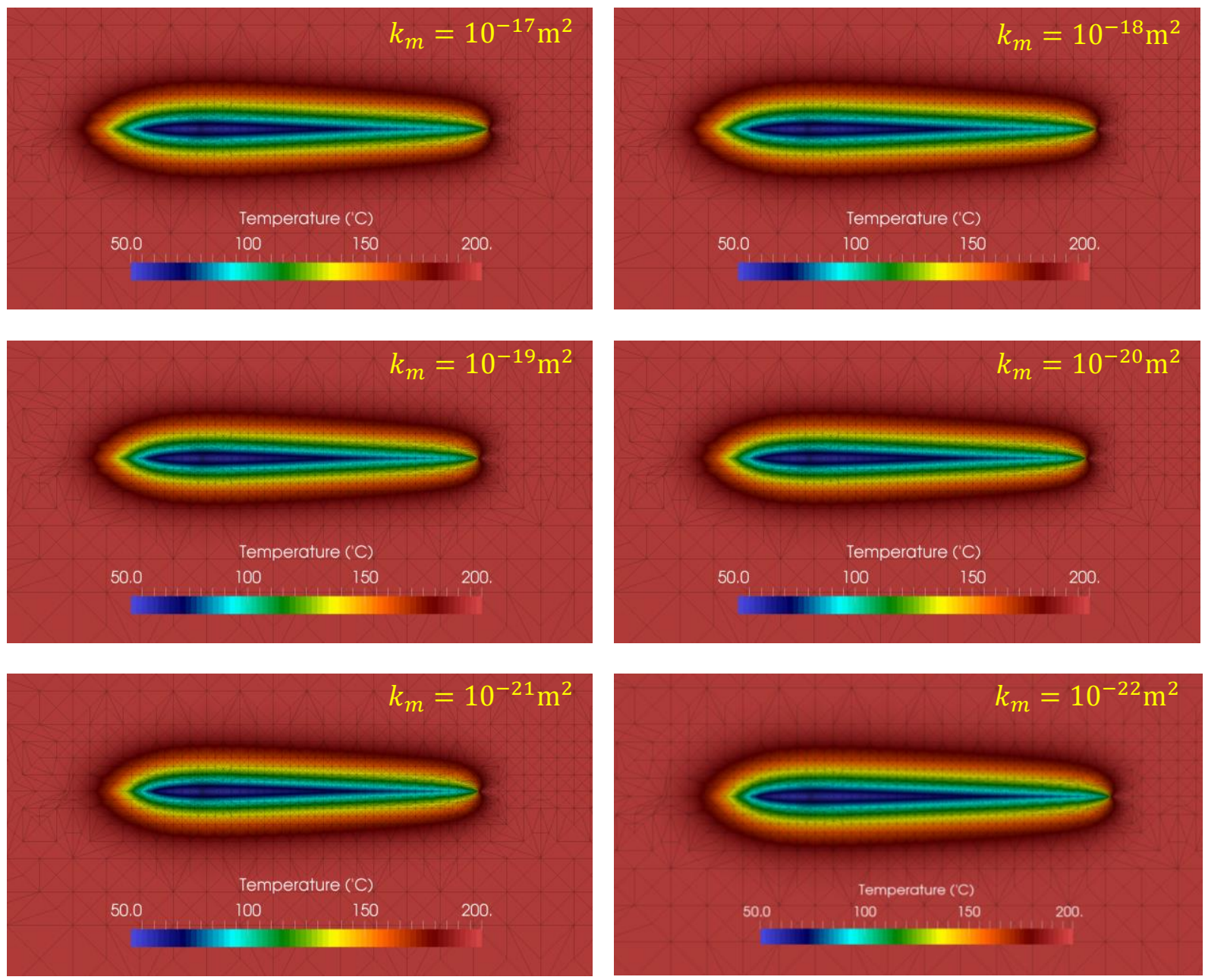

Figure 4. The matrix temperature distribution on a vertical plane passing through the injection and production points for different matrix permeabilities after 30 years 

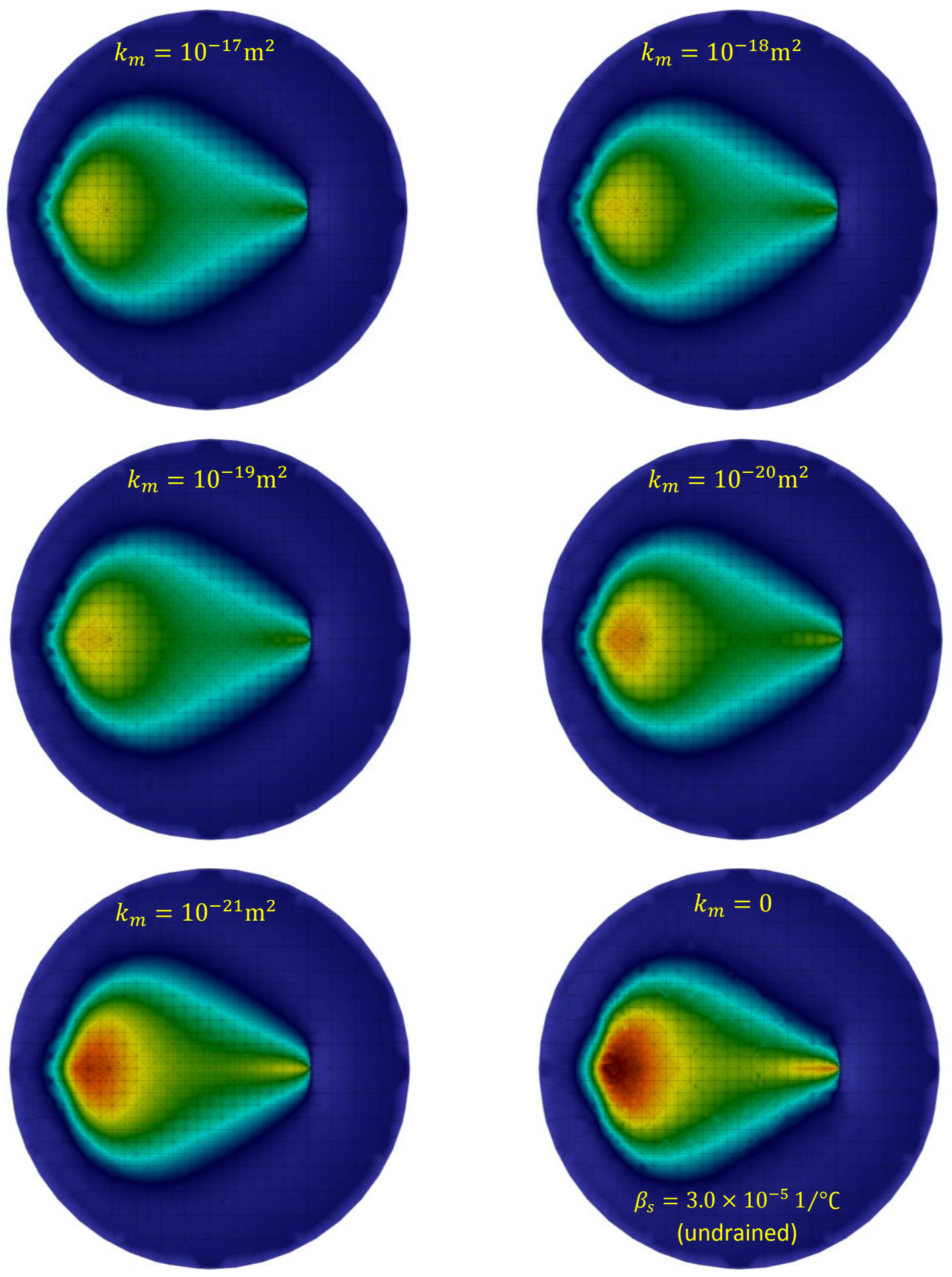

Aperture (m)

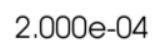

0.0005

1.000 e-03

Figure 5. The fracture aperture distribution for different matrix permeabilities after 30 years 
(a)

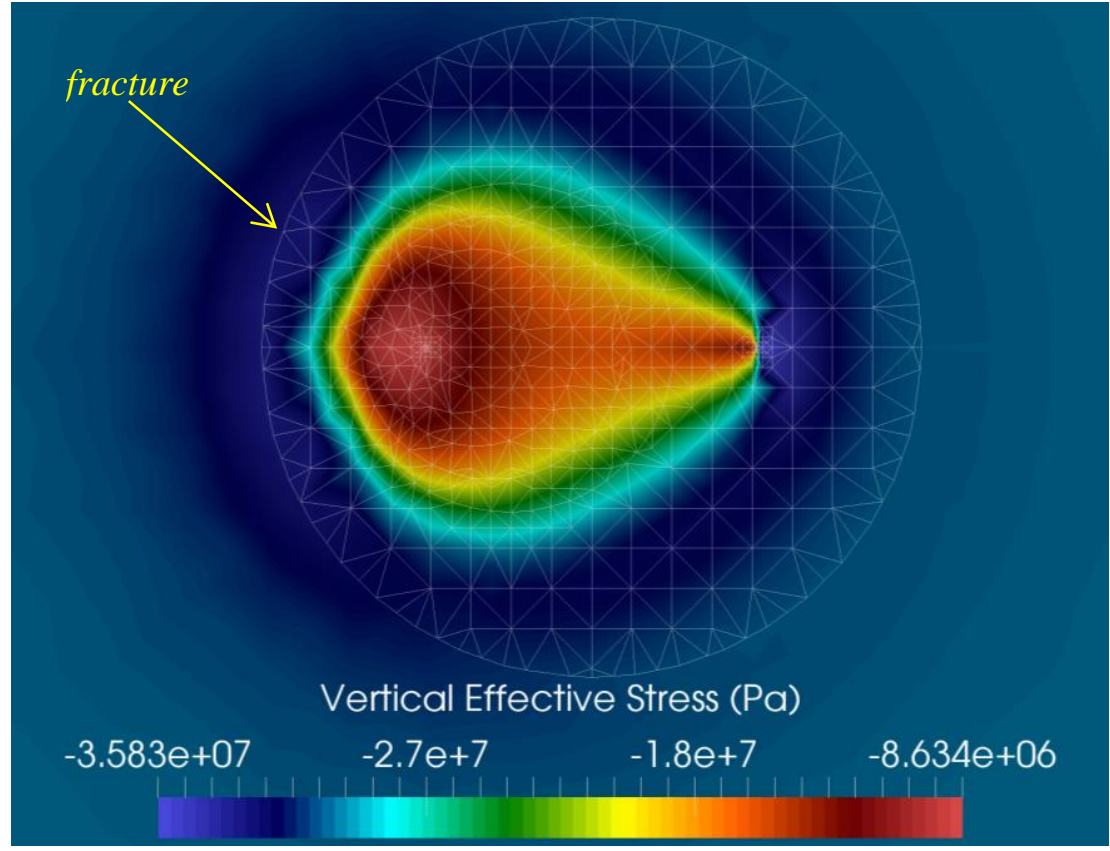

(b)

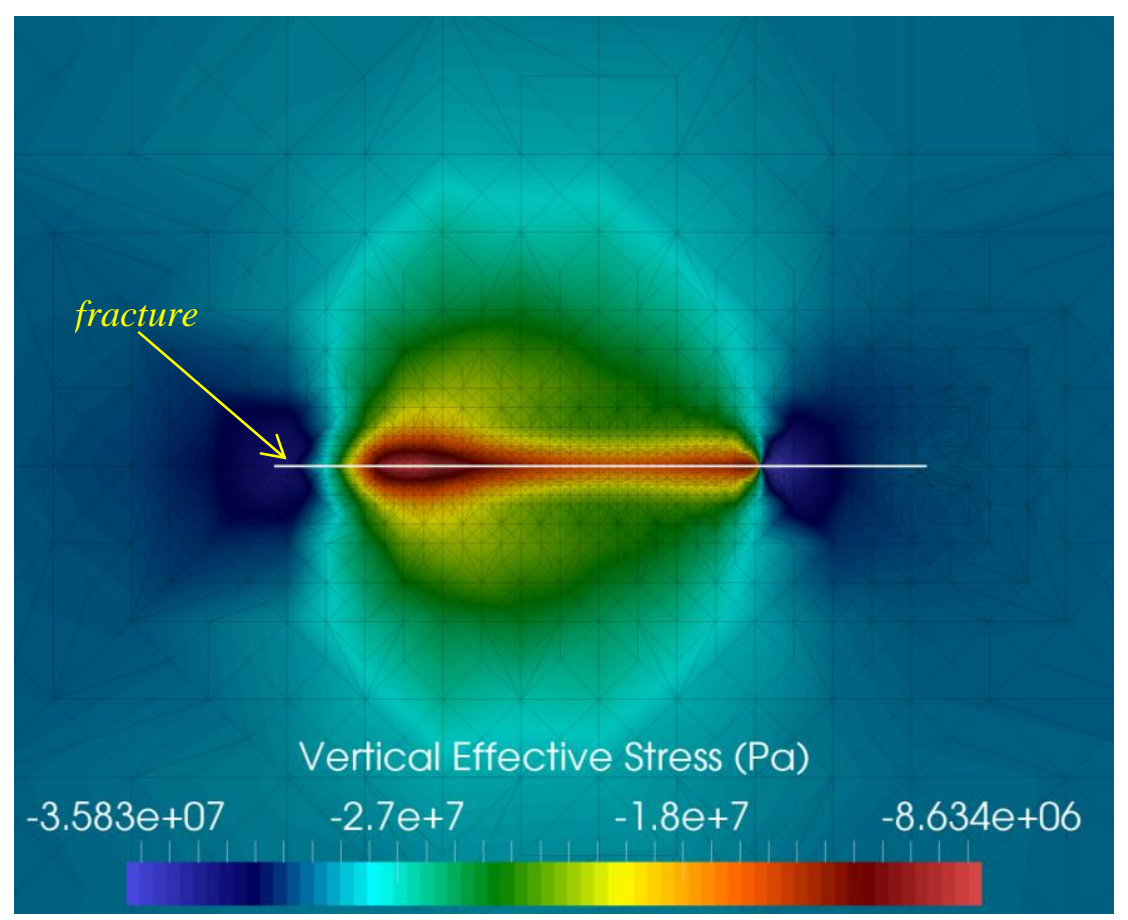

Figure 6. The vertical effective stress distribution on a horizontal plane (a) and on a vertical plane (b) passing through the injection and production points for the case with $k_{m}=10^{-20} \mathrm{~m}^{2}$ and $\alpha=1$ after 30 years 

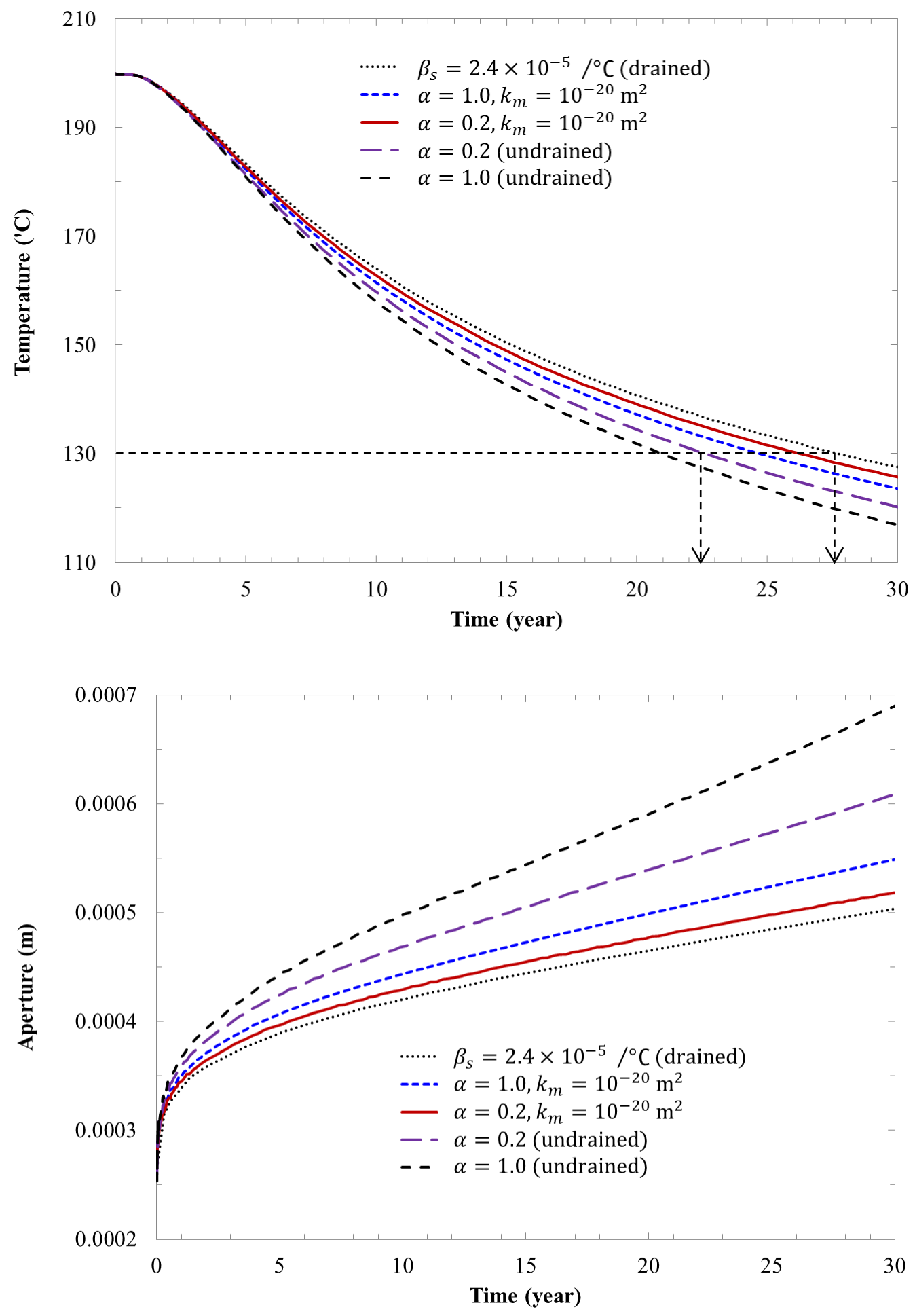

Figure 7. The fluid temperature at producer and the fracture aperture at injection point versus injection time for different Biot coefficients 

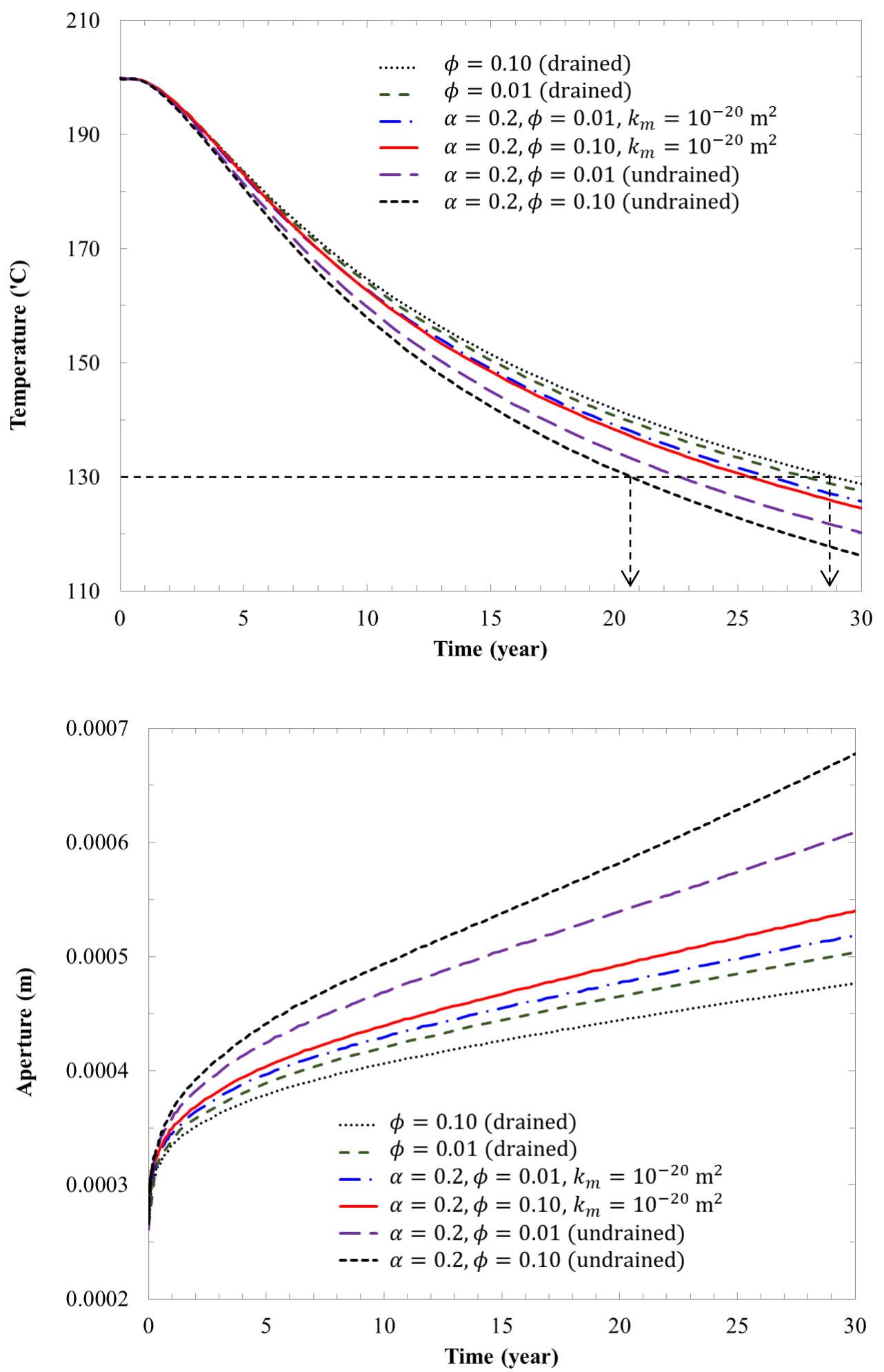

Figure 8 . The fluid temperature at producer and the fracture aperture at injection point versus injection time for different matrix porosities 


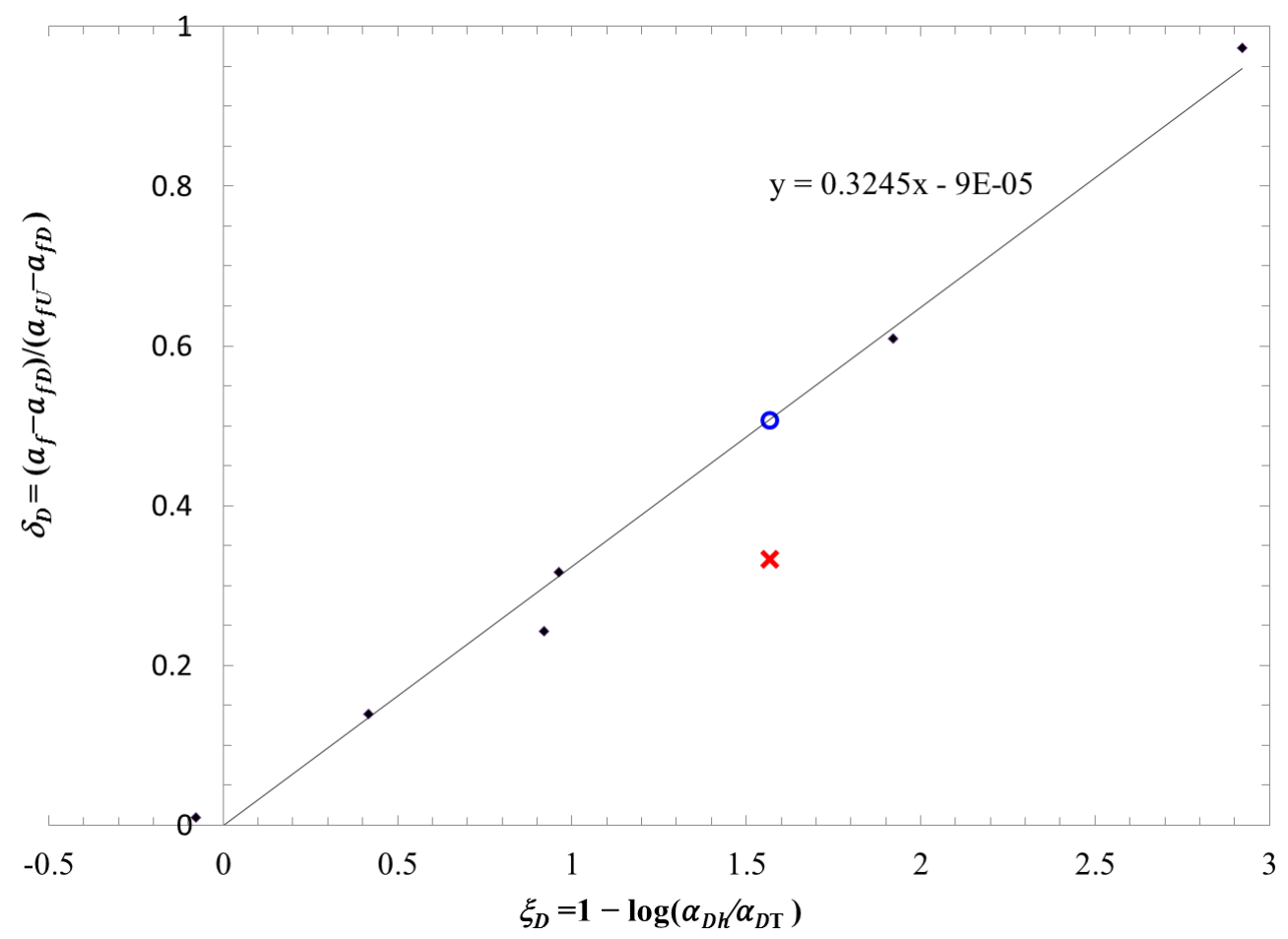

Figure 9. Dimensionless drainage parameter $\delta_{D}$ versus dimensionless diffusion parameter $\xi_{D}$. Blue circle shows the test case simulated using the full thermoporoelastic model, the red cross shows the test case simulated using the modified thermal expansion coefficient 

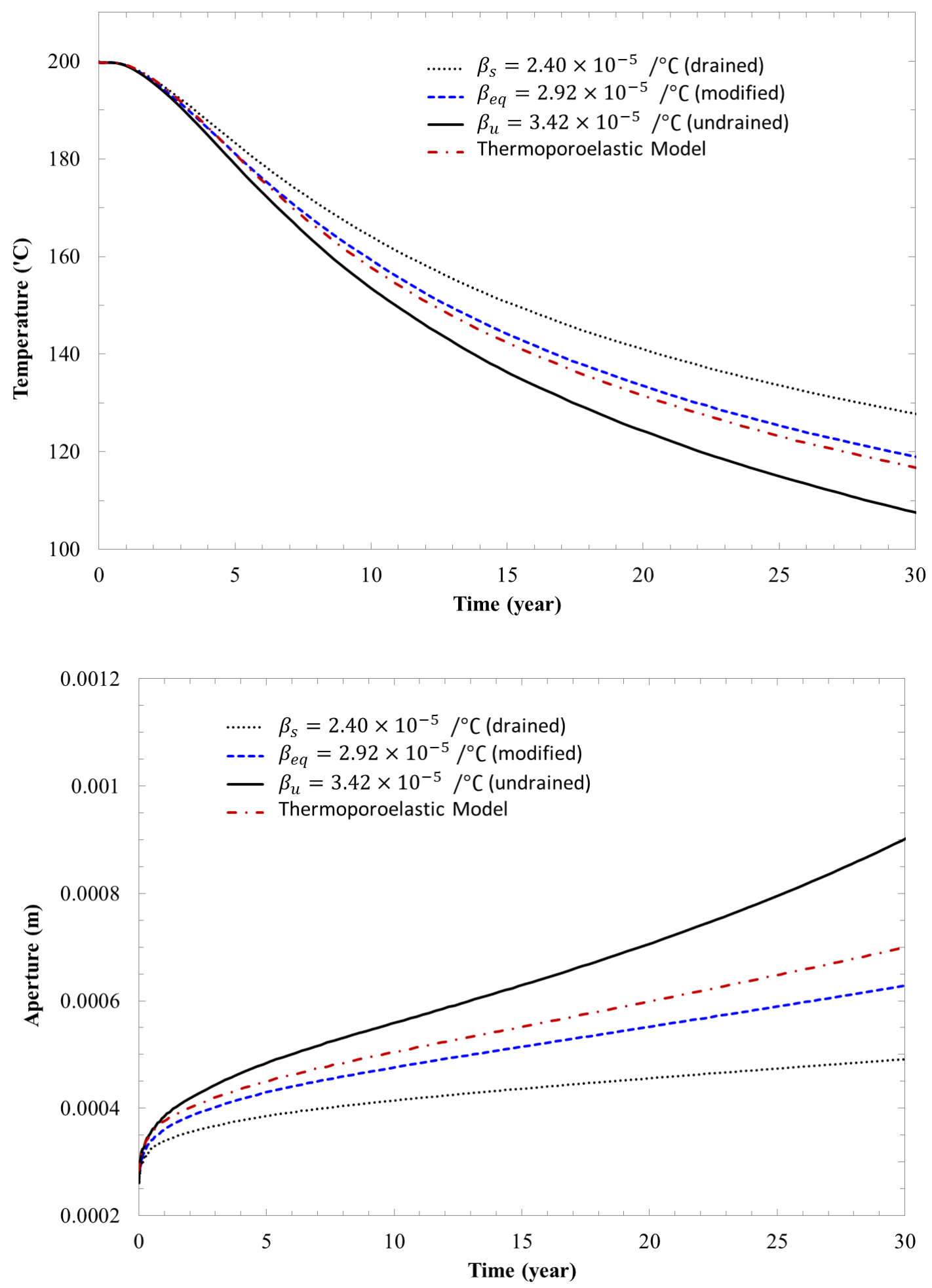

Figure 10. The fluid temperature at producer and the fracture aperture at injection point versus injection time for the test case with modified thermal expansion coefficient 